\title{
Regression Analysis on Agent Roles in Personal Knowledge Management Processes: Significance of a Connect Agent in Mediating Human's Personal Knowledge Management
}

\author{
Shahrinaz Ismail \\ Malaysian Institute of Information Technology \\ Universiti Kuala Lumpur - MIIT \\ Kuala Lumpur, Malaysia \\ shahrinaz@unikl.edu.my
}

\author{
Mohd Sharifuddin Ahmad \\ Zainuddin Hassan \\ College of Information Technology \\ Universiti Tenaga Nasional \\ Kajang, Selangor, Malaysia. \\ \{sharif, zainuddin\}@uniten.edu.my
}

\begin{abstract}
Across the literature, there is a gradual development of research on personal knowledge management (PKM) from theoretical to technical perspective on managing personal knowledge over the computer and Internet technologies. This research domain has aroused the interest of researchers with the introduction of a PKM model to accommodate the understanding of PKM among knowledge workers. In this model, called the GUSC model, there are four main processes, which are Get knowledge, Understand knowledge, Share knowledge and Connect to knowledge sources. This model entails four cognitive enablers that are proposed to mediate the PKM processes. This paper analyses the quantitative data on the GUSC model to further understand the roles of software agents in mediating human's PKM processes. It also analyses the role of cognitive enablers as mediating factors for the PKM processes, which are seen as potential strong notions for software agency. The results of the analysis show the significance of 'connect' as a role of an agent that depends on the rest of the factors. Based on the quantitative findings, it is recommended that the GUSC model is used to conceptualise an agent-based system, with cognitive enablers to determine the appropriate agent-mediated structure for the system.
\end{abstract}

Keywords: Personal knowledge management, GUSC model, cognitive enablers, software agent technology, nodal approach.

\section{Introduction}

Under the realm of artificial intelligence lies various technologies that contribute to intelligence of devices and programs, especially in mediating human knowledge workers in their daily tasks and routines. These intelligent technologies are predicted to reach their peak of usage in the year 2015, regardless of the change in technology or change in user trends on technology that may evolve by that year (Solachidis et al., 2010). While many would dispute this statement, it is undeniable to say that research is progressing in applying intelligence in tools and technologies, contributing to the growth of artificial intelligence domain. This prediction also caters for the use of software agent technology, in which the roles of software agents are deemed important to exhibit the intelligence of the overall system they 'live' in.

In recent years, especially with the boost of Internet with Web 2.0, the trend of performing tasks by knowledge workers has evolved tremendously from the past decade. Knowledge workers tend to find their own ways to look for the right people who can help them in understanding new knowledge in order to get their jobs done. With the help of the facilitating technologies, connecting to other people and experts becomes a need. In managing this necessity, the term 'personal knowledge management' (PKM) has emerged as an important area of knowledge management.

Across the literature, research in personal knowledge management (PKM) has evolved from theoretical to technical perspective on managing personal knowledge over the computer and Internet technologies. This research domain has aroused the interest of researchers with the introduction of the GUSC model to accommodate the understanding of PKM among knowledge workers. Sondari (2013) exploits this model for furthering her research in Asia on the concept of PKM 2.0 based on Web 2.0 platform.

In contributing to the research on the GUSC Model, this paper investigates the four main processes proposed in the model (i.e. Get, Understand, Share and Connect), which entails four cognitive enablers to mediate human knowledge workers in the whole PKM processes (i.e. Method, Identify, Decide and Drive). The key point of this model is 
'connectivity', and this paper analyses the significance of 'connectivity' in both the GUSC model (theoretical) and software agent mediation (technical).

This paper aims to validate the GUSC model as a foundation for applying the model in a multi-agent system development. This validation strongly justifies the existence of PKM at individual level with a set of processes and variables defined in the software agent environment and system structure. In analysing the quantitative data to validate the GUSC model, the following hypotheses are proposed:

H1: Collinearity exists between Get, Understand, Share and Connect in the GUSC Model.

H2: Cognitive enablers are the control variables in the GUSC Model.

H3: Connect is the most significant role in mediating human's PKM.

\section{Related Works}

This section presents the literature review and analysis from two research perspectives: knowledge management and intelligent software agent technology. These two domains are found to be inter-related in recent research conducted on knowledge workers, with the aim to mediate the management of personal knowledge. Due to the numerous literature in both domains, the focus of this review is only on those related to and deriving from the understanding of agents' roles and the way the PKM concept is applied to software agent characteristics.

\subsection{Personal Knowledge Management (PKM)}

Individuals are the essential core of an organisation and due to this fact, it is necessary for organizations to focus on the needs of personal knowledge as well as the broad, enterprise-wide assets (Zhang, 2008). Myint (2004) supported this argument by emphasising the value of PKM in the workplace as the importance of knowledge management (KM) for individuals. This manifests the significance of PKM among knowledge workers, which attracts the interests of researchers worldwide. For example, Pettenati et al. (2007) explored the essential PKM skills, by investigating the patterns against the current Web 2.0 technologies. The advantages of Web 2.0 technologies in supporting PKM are also emphasised by Razmerita, Kirchner and Suzina (2009), who are more technical in suggesting the tools for managing knowledge at individual and organisational levels.

In the literature, the important aspect that is emphasised by researchers is the 'people factor', but a core focus of PKM, according to Verma (2009), is personal inquiry, i.e., a quest to find, connect, learn and explore. Summarily, Figure 1 shows the PKM processes that authors found to be necessary for knowledge workers to perform in managing knowledge (Avery et al., 2001; Pettenati et al., 2007; Grundspenkis, 2007; Razmerita et al., 2009; Verma, 2009; Jarche, 2010; Martin, 2000; McFarlane, 2011), which collectively defines the meaning of PKM.

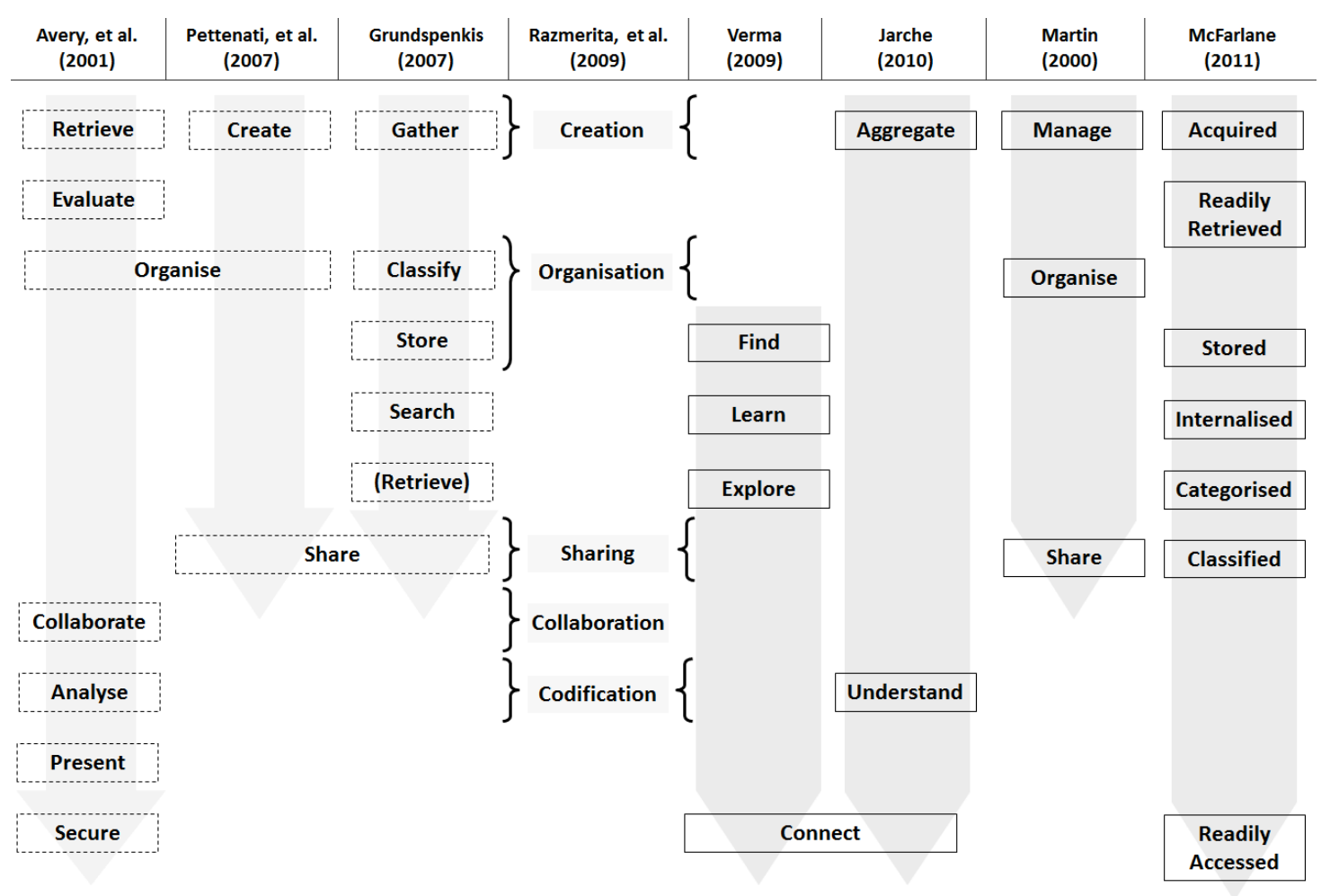

Figure 1. Comparison of PKM processes flow 
In Asia, a concept of get-understand-share-connect has been introduced in recent years to complement the concept of PKM processes. The PKM processes, according to this model, consist of tasks performed over the computer and Internet technologies, to get/retrieve knowledge (e.g. online search, RSS feed, aggregation, 'follow' shared updates), understand/analyse knowledge (e.g. summarise, review, write research papers), share knowledge (e.g. blog, RSS to blog, share link with reviews, tag people when sharing links, wiki), and connect to other knowledge sources and/or knowledge experts (e.g. from comments by others, from votes by others, from 'following' other's work or profile, email, online messages) (Ismail \& Ahmad, 2012). This model, known as the GUSC Model, is somehow similar to the SECI Model introduced by the renowned Nonaka and Takeuchi (1995), in which the cycle of socialisation, externalisation, internalisation and combination is a necessity to create new knowledge in an organisation. Figure 2 shows how the GUSC Model and SECI Model are related, depicting that the sequence of get-understand-share-connect to be of no fixed order.

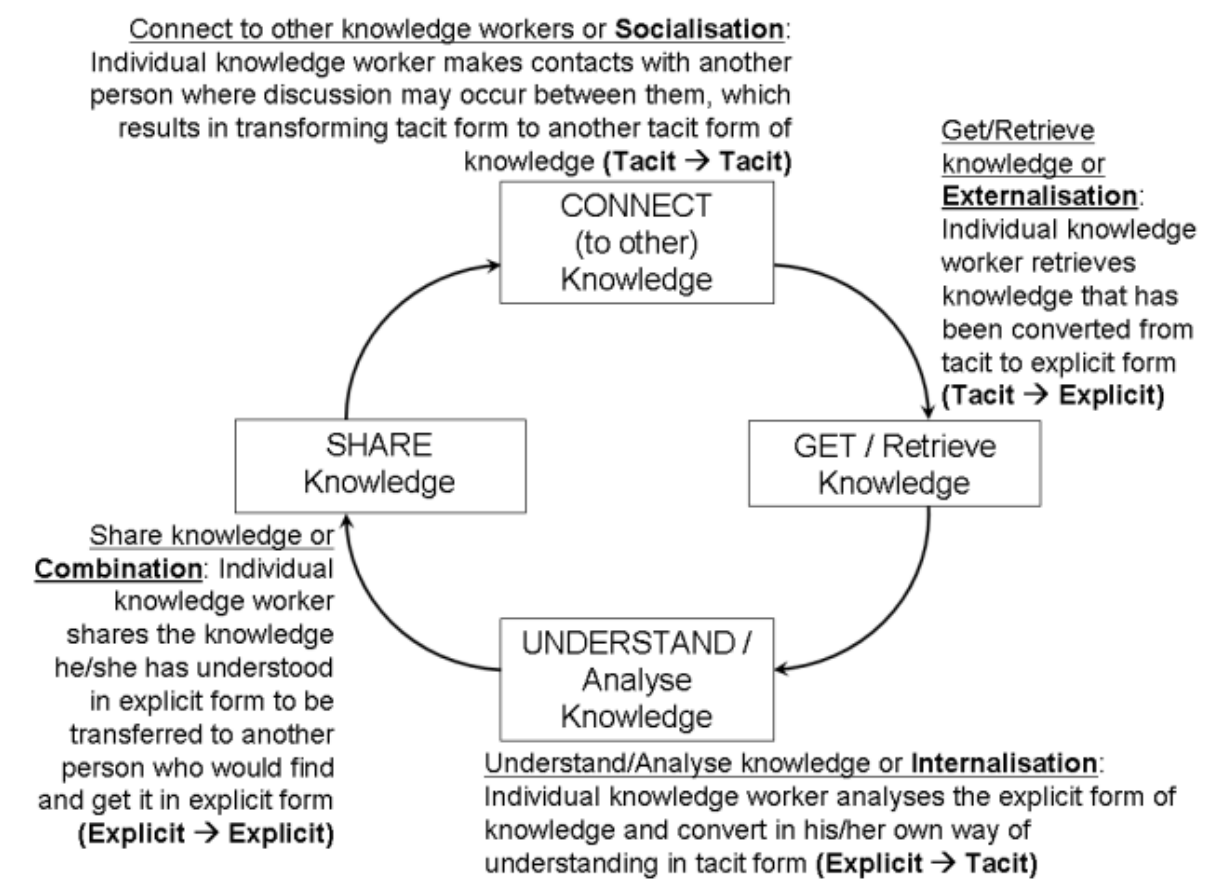

Figure 2. GUSC Model on PKM processes

The GUSC Model entails four cognitive enablers, derived from the findings of a recent questionnaire survey presented in 2011 (Ismail \& Ahmad, 2011). While knowledge organisations have KM processes and drivers (Awad \& Ghaziri, 2004), individual knowledge workers are expected to have a similar kind of 'drivers', called 'enablers', to manifest the PKM processes. Figure 3 shows a PKM framework that includes four cognitive enablers (i.e. method, identify, decide and drive) that become the 'drivers' for get/retrieve, understand/analyse, share, and connect processes.

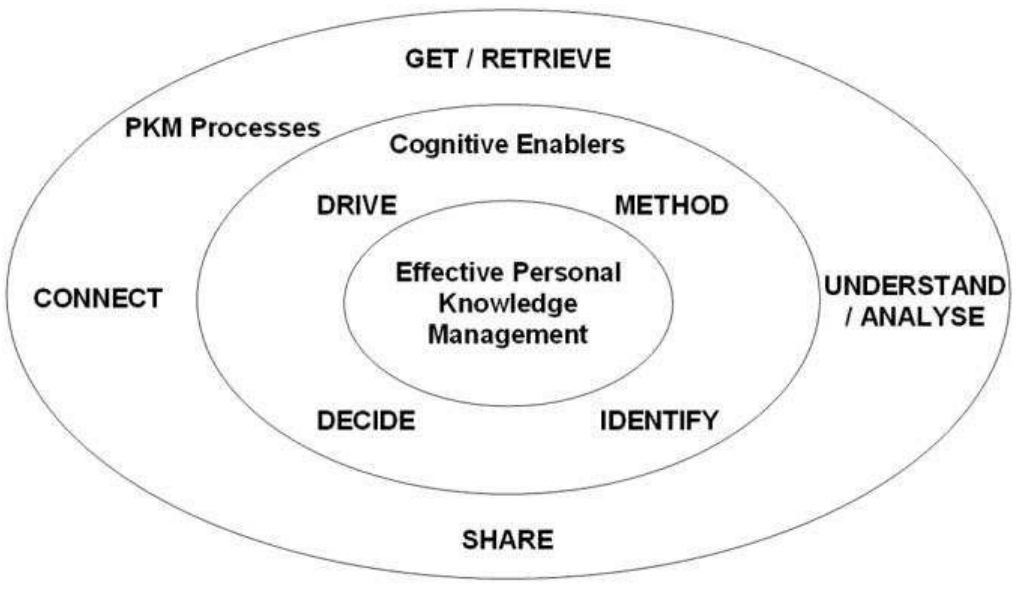

Figure 3. PKM Framework with cognitive enablers 
In order to prove the hypotheses, this research is based on the PKM framework shown in Figure 3.

\subsection{Software Agent Technology}

Software agents are entities that function continuously and autonomously in a particular environment that is often inhabited by other agents and processes (Bradshaw et al., 1997). They are expected to have the abilities and intelligence to learn from their experience, communicate and cooperate with people and other agents, and roam within networks and Semantic Web. Most definitions of software agents have similarities in terms of being autonomous, because this behaviour is required to interact with its environment or surrounding. Among the most often quoted definitions on software agents are:

i. "programs that engage in dialogs and negotiate and coordinate the transfer of information" (Coen, 1991);

ii. "anything that can be viewed as perceiving its environment through sensors and acting upon that environment through effectors" (Russell \& Norvig, 1995);

iii. "software entities that carry out some set of operations on behalf of a user or another program with some degree of independence or autonomy, and in so doing, employ some knowledge or representation of the user's goals or desires" (Gilbert et al., 1995);

iv. "autonomous agents are computational systems that inhabit some complex dynamic environment; sense and act autonomously in this environment and by doing so realise set of goals or task for which they are designed" (Maes, 1995);

v. "an encapsulated computer system that is situated in some environment and that is capable of flexible action in that environment in order to meet its design objectives" (Jennings et al., 2000).

This research focuses on the characteristics to define the software agent as being autonomous, reactive, proactive, communicative, adaptive, goal-oriented, cooperative, reason, and flexible, as adapted from Paprzycki and Abraham (2003)

The two major categories of software agents that characterise the agents further are weak notions (i.e. autonomous, sociable, reactive, and proactive) and strong notions (i.e. ability to do humanistic emotions like having beliefs, desires, intentions, diligence, knowledge, obligation, commitment, and many others) (Wooldridge \& Jennings, 1995). The strong notions are derived from the humanistic concepts that predefine the roles the agents play in mediating their human counterparts. Among the examples of humanistic attitudes found suitable in representing agents include belief and knowledge (i.e. information attitudes), and desire, intention, obligation, commitment and choice (i.e. category of pro-attitudes).

In relating the technical concept of software agents to the theoretical concept of knowledge management (KM), we argue that the basic features of agents (i.e. social ability, autonomy, re- and pro-activeness) can alleviate several drawbacks of KM technology (van Elst, Dignum, \& Abecker, 2003). On a more practical note, Guizzardi et al. (2003) presented an analysis and modeling case study for agent-mediated knowledge management in educational environments, where an agent-based peer-to-peer helpdesk system was developed to support extra-class interactions among students and teachers.

\subsection{PKM in Multi-Agent Roles}

A study on a related field manifests social intelligence as a consequence of the nodal approach to agent-mediation in PKM (Ismail, Ahmad \& Hassan, 2012). The interactions between human and his/her agent within a node and the agent's interaction with other agents within and across organisational boundaries between nodes provide a favourable and conducive environment for social intelligence (Ismail, Ahmad \& Hassan, 2012). However, "in reality, interactive systems may not understand social and natural rules of interaction but what people perceive to be true is more influential than the objective reality" (Green \& de Ruyter, 2009). It is true for agent-mediated PKM as well, but with a possibility of being programmed to implement the social and natural rules of interaction using the strong notion of agency (Ismail, Ahmad \& Hassan, 2012).

Social intelligence can support active social networking processes to foster knowledge sharing and management of personal knowledge (Ismail, Ahmad \& Hassan, 2012), and social network should be a good platform to proof that social intelligence in managing personal knowledge exists. A community model is suggested as it "emphasises the fact that knowledge is continuously recreated and reconstructed through dynamic, interactive and social networking activity" (Razmerita, Kirchner \& Suzina, 2009), and this can be exploited by the social ability of an agent. Nonaka and 
Takeuchi (1995) supported this belief years before the emergence of social network, with their organisational theory that highlights "the fact that knowledge is embedded and constructed through social interactions" (Razmerita, Kirchner \& Suzina, 2009).

Social intelligence is the manifestation of socialisation between software agents and their human counterparts, as shown in Table I. Due to the different environments between organisational environment (postulated in SECI Model) and agent environment (as shown in Table I), the sequence of processes of knowledge being translated between tacit and explicit forms differ. Table I explains the processes when software agents are used to mediate the task of finding knowledge experts. Hence, the actors in Table I include both the human knowledge workers and the mediating agents (Ismail, Ahmad \& Hassan, 2012).

Table I. Social Intelligence in Social Network

\begin{tabular}{|l|l|}
\hline \multicolumn{1}{|c|}{ SECI Interactions } & \multicolumn{1}{c|}{ Social Interactions within Agent Environment } \\
\hline $\begin{array}{l}\text { Externalisation } \\
\text { Tacit } \rightarrow \text { Explicit }\end{array}$ & $\begin{array}{l}\text { Human } \rightarrow \text { Agent } \\
\text { The task of finding the knowledge expert is mediated by an agent, when the } \\
\text { knowledge seeker SHARES by passing the messages and documents to the agent } \\
\text { in explicit form. }\end{array}$ \\
\hline $\begin{array}{l}\text { Combination } \\
\text { Explicit } \rightarrow \text { Explicit }\end{array}$ & $\begin{array}{l}\text { Agent } \rightarrow \text { Agent } \\
\text { Agent GETS the messages and documents from other agents, in explicit form. }\end{array}$ \\
\hline $\begin{array}{l}\text { Internalisation } \\
\text { Explicit } \rightarrow \text { Tacit }\end{array}$ & $\begin{array}{l}\text { Agent } \rightarrow \text { Human } \\
\text { The knowledge seeker UNDERSTANDS the messages and documents found by } \\
\text { the agents. }\end{array}$ \\
\hline $\begin{array}{l}\text { Socialisation } \\
\text { Tacit } \rightarrow \text { Tacit }\end{array}$ & $\begin{array}{l}\text { Human } \rightarrow \text { Human } \\
\text { The knowledge seeker and the knowledge expert (the agents' human counterparts) }\end{array}$ \\
\hline
\end{tabular}

In the nodal approach, which corresponds to the model of social network, an individual knowledge worker manages his/her personal knowledge by working cooperatively with a software agent in a virtual workspace called a node (Ismail, Ahmad \& Hassan, 2012). A node consists of a knowledge worker and one or more (role) agents, to perform some supporting roles of the knowledge worker. The knowledge worker has a set of functions for the PKM processes, some of which could be delegated to the agents. Figure 4 shows how a knowledge worker (in Node 1) performs normal offline interaction with another knowledge worker (Node 2) while his/her role agents interact with the other agent for information and resource exchanges, on behalf of their respective human counterparts. The letters $G, U, S$ and $C$ indicated in each node represent the role agents Get, Understand, Share and Connect, as they mediate for their human counterparts.

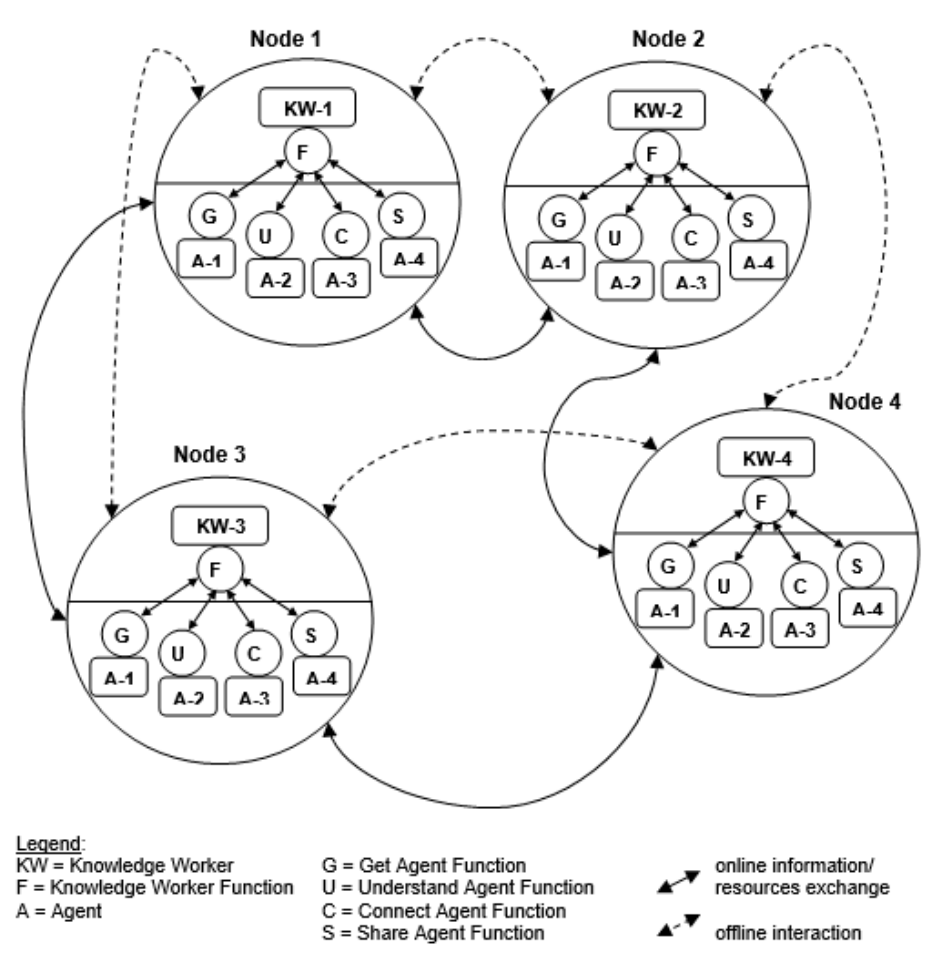


Figure 4. A nodal approach of multi-agent system

\section{Methodology}

A questionnaire survey was conducted based on theoretical sampling, according to a random non-probabilistic purposive sampling procedure. This sampling technique is suggested by Wiedermann (1995) for a survey in which the features and the extension of the basic population are not known in advance. The objective of the survey is two-fold: to identify the approaches used by knowledge workers in managing their personal knowledge; and to verify the variables proposed by the GUSC model as cognitive enablers. A pilot test on the questionnaire design was implemented on a sample of five experts, before the questionnaire survey was fully conducted.

The questionnaire design consists of 13 closed questions organised in five parts, as follows:

Part 1. PKM Awareness

Question 1: Self-practice of PKM

Question 2: Effectiveness of self PKM

Part 2. Understanding the Individual's Personal Knowledge Management

Question 3: How do you perform a task?

Question 4: In what ways do you identify knowledge sources?

Question 5: How do you manage your personal knowledge? (Subdivided into: get knowledge, understand/analyse knowledge, share/publish knowledge, and connect)

Part 3. Understanding the Knowledge Sources

Question 6: What are the knowledge sources you often seek?

Question 7: How do you manage your identified knowledge sources?

Question 8: How do you interpret and exploit available data as and when it is needed?

Part 4. Individual Characteristics in 'Locating' Knowledge Experts

Question 9: What makes you decide on which approach to take in seeking knowledge experts?

Question 10: What drives you to seek knowledge experts?

Part 5. Demographics

Question 11: Industry of work

Question 12: Level of position

Question 13: Age range

Question 5 of the questionnaire is the main part that requests for feedback on personal knowledge management processes, namely get knowledge, understand knowledge, share knowledge and connect (i.e. GUSC). In supporting Question 5, Questions 3, 4, 9 and 10 refers to the cognitive enablers, namely Method (Question 3), Identify (Question 4), Decide (Question 9) and Drive (Question 10). The questionnaire was designed according to the flow of understanding the individual's PKM (Part 2), the knowledge sources (Part 3) and the characteristics in finding knowledge experts (Part 4), hence the position of the questions on cognitive enablers to be before and after the questions on GUSC processes.

Out of 501 questionnaires successfully distributed, there was a return rate of 24 percent $(24 \%)$ of completed questionnaires. The respondents are from the service industry (46.41\%), education industry (38.14\%) and manufacturing industry (15.25\%). The majority of the respondents are between the ages of 21 to $30(34.75 \%)$, whereas the positions these respondents hold are executives or lecturers $(55.08 \%)$. These respondents represent the most fundamental characteristic of many organisations, which is the group of knowledge workers who relies on their effectiveness in managing personal knowledge, especially in terms of understanding new knowledge from referring to knowledge experts.

The general findings of this questionnaire survey are presented in Ismail and Ahmad (2011), which highlights the significant discovery of heavy reliance on the email system to manage personal knowledge among the knowledge workers.

\section{Results and Findings}

The results and findings are presented in some sequence. The validity and reliability of the questionnaire design are tested using factor analysis and Cronbach's alpha in SPSS. This is followed by a detailed analysis on the GUSC model and its cognitive enablers in terms of correlations, collinearity, the goodness of fit of the model, and coefficients analysis, to prove the three proposed hypotheses. 


\subsection{Validity and Reliability of Questionnaire Design}

In interpreting the validity of data, the number of variables used in the questionnaire design needs to be measured and tested using factor analysis. "The most important factors in determining reliable factor solutions are the absolute sample size and the absolute magnitude of factor loadings" (Field, 2000), and the more frequent and higher the loadings are on a factor, the smaller the sample.

Two rounds of factor analysis were conducted: the first is to analyse the communalities of each item in the variables and the second analyses the communalities of each variable in general. Communalities indicate the amount of variance in each variable that is accounted for. In SPSS, the values shown as extraction communalities are the ones used to interpret the validity of the data.

The total number of responses $(n=118)$ are found valid in the factor analysis test, with all items in each variable having high communality values, which is above 0.630 . The result of the communalities on the variables in general also shows high values except for Decide variable (0.484) and Understand (0.531), as shown in Figure 5. The small values for these two variables mean that the variables do not fit well with the factor solution, but on the other hand the value of 0.500 and above shows that the sample size is enough for further analysis.

\section{Communalities}

\begin{tabular}{|l|r|r|}
\hline & \multicolumn{1}{|c|}{ Initial } & Extraction \\
\hline Get & 1.000 & .664 \\
Understand & 1.000 & .531 \\
Share & 1.000 & .751 \\
Connect & 1.000 & .784 \\
Method & 1.000 & .852 \\
Identify & 1.000 & .761 \\
Decide & 1.000 & .484 \\
Drive & 1.000 & .608 \\
\hline
\end{tabular}

Extraction Method: Principal Component Analysis.

Figure 5. Communalities on the variables in general $(n=118)$

Cronbach's alpha reliability coefficient measures the internal consistency of the variables being tested by looking at how a set of items are closely related as a group. The values derive different meanings according to the range they belong to: $\alpha>0.9$ is excellent, $0.8<\alpha<0.89$ is good, $0.7<\alpha<0.79$ is acceptable, $0.6<\alpha<0.69$ is questionable, $0.5<$ $\alpha<0.59$ is poor, and $\alpha<0.5$ is unacceptable. This research takes into account that the Cronbach's alpha ( $\alpha$ ) is acceptable from 0.70 onwards, considering 0.70 is the cutoff value for being acceptable.

Table II. Reliability of Questionnaire Design

\begin{tabular}{|l|c|c|}
\hline \multicolumn{1}{|c|}{ Variables } & Cronbach's alpha $(\boldsymbol{\alpha})$ & Number of Items \\
\hline GET & 0.884 & 8 \\
\hline UNDERSTAND & 0.715 & 5 \\
\hline SHARE & 0.917 & 11 \\
\hline CONNECT & 0.869 & 9 \\
\hline METHOD & 0.951 & 17 \\
\hline IDENTIFY & 0.904 & 9 \\
\hline DECIDE & 0.735 & 6 \\
\hline DRIVE & 0.976 & 15 \\
\hline
\end{tabular}

In order to get the highest possible value for Cronbach's alpha, the reliability test was done repetitively and an item is removed in each analysis cycle as suggested by SPSS. Table II shows the reliability of each variable after the items are removed from the original number to get the highest value for Cronbach's alpha $(\alpha)$. The results in Table II shows that all variables are reliable, including the Decide variable that receives a low validity value in Figure 5.

Another round of reliability test was conducted to understand the consistency of the eight main variables. Figure 6 shows the result from SPSS, showing the strength in Cronbach's alpha value of 0.803 , which is good and meaningful to indicate that the variables are reliable. 
Reliability Statistics

\begin{tabular}{|c|c|c|}
\hline $\begin{array}{c}\text { Cronbach's } \\
\text { Alpha }\end{array}$ & $\begin{array}{c}\text { Cronbach's } \\
\text { Alpha Based } \\
\text { on } \\
\text { Standardized } \\
\text { Items }\end{array}$ & $N$ of ltems \\
\hline .803 & .874 & 8 \\
\hline
\end{tabular}

Figure 6. Reliability statistics on the eight variables in general

\subsection{Supporting the Hypotheses}

In order to prove the hypotheses, the collected data were analysed using regression method in SPSS, to generate the value of Pearson correlation coefficient $(r)$ in further understanding the relationship between every two variables. This correlation coefficient helps in examining and interpreting the degree of relationship between the eight main variables. Positive value shows a positive relationship between the variables, whereas negative value shows a negative relationship.

Figure 7 shows the Pearson correlations results from SPSS, which indicates positive relationships for all intervariables, with high values for Get-Connect $(+0.616)$, Share-Connect $(+0.758)$, Get-Share $(+0.632)$, Get-Drive $(+0.619)$, and Method-Identify $(+0.692)$. Other relationships also produce positive and quite strong values (i.e. above 0.2 ), showing that the relationships exist in a linear form.

The important interpretation derived from Figure 7 is the fact that all correlations are highly significant, with the significance level value less than 0.05 (shown in row Sig. (1-tailed) for all variables). It shows that the collinearity exist, even if some of the relationships are not as high as +0.6 . Table II shows the summary of collinearity that exists between the variables in GUSC model, which supports the hypothesis H1: Collinearity exists between Get, Understand, Share and Connect in GUSC Model, at high significance level.

\begin{tabular}{|c|c|c|c|c|c|c|c|c|c|}
\hline \multicolumn{10}{|c|}{ Correlations } \\
\hline & & Connect & Get & Understand & Share & Method & Identify & Decide & Drive \\
\hline \multirow[t]{8}{*}{ Pearson Correlation } & Connect & 1.000 & .616 & .583 & .758 & .306 & .440 & .478 & .562 \\
\hline & Get & .616 & 1.000 & .462 & .632 & .358 & .432 & .470 & .619 \\
\hline & Understand & .583 & .462 & 1.000 & .510 & .259 & .406 & .421 & .406 \\
\hline & Share & .758 & .632 & .510 & 1.000 & .242 & .324 & .406 & .427 \\
\hline & Method & .306 & .358 & .259 & .242 & 1.000 & .692 & .365 & .464 \\
\hline & Identify & .440 & .432 & .406 & .324 & .692 & 1.000 & .348 & .426 \\
\hline & Decide & .478 & .470 & .421 & .406 & .365 & .348 & 1.000 & .591 \\
\hline & Drive & .562 & .619 & .406 & .427 & .464 & .426 & .591 & 1.000 \\
\hline \multirow[t]{8}{*}{ Sig. (1-tailed) } & Connect & & .000 & .000 & .000 & .000 & .000 & .000 & .000 \\
\hline & Get & .000 & & .000 & .000 & .000 & .000 & .000 & .000 \\
\hline & Understand & .000 & .000 & & .000 & .002 & .000 & .000 & .000 \\
\hline & Share & .000 & .000 & .000 & & .004 & .000 & .000 & .000 \\
\hline & Method & .000 & .000 & .002 & .004 & & .000 & .000 & .000 \\
\hline & Identify & .000 & .000 & .000 & .000 & .000 & & .000 & .000 \\
\hline & Decide & .000 & .000 & .000 & .000 & .000 & .000 & . & .000 \\
\hline & Drive & .000 & .000 & .000 & .000 & .000 & .000 & .000 & \\
\hline
\end{tabular}

Figure 7. Correlations among the eight variables

Table III highlights the relationships for a case when Connect is defined as dependent variable. These relationships are further analysed in the next step.

To test the existing collinearity, the collinearity diagnostics is further interpreted. This analysis was done by defining the variables according to the following roles: Connect as dependent variable; Get, Understand and Share as independent variables; and Method, Identify, Decide and Drive as additional independent variables. The first model (shown in the first row in Figure 8 as Model 1) shows the collinearity diagnostics when the three independent variables are included in the model, whereas the second model (shown as Model 2 in Figure 8) shows the collinearity diagnostics when the additional four independent variables are included in the former model (i.e. the number of independent variables becomes 7). 
Table III. Relationship between the Variables in GUSC Model

\begin{tabular}{|l|c|c|}
\hline \multicolumn{1}{|c|}{ Relationships } & Pearson Correlation $(\boldsymbol{r})$ & Sig. (1-tailed) \\
\hline Get-Connect & $+\mathbf{0 . 6 1 6}$ & $<\mathbf{0 . 0 0 5}$ \\
\hline Get- Understand & +0.462 & $<0.005$ \\
\hline Get-Share & +0.632 & $<0.005$ \\
\hline Understand-Share & +0.510 & $<0.005$ \\
\hline Understand-Connect & $+\mathbf{0 . 5 8 3}$ & $<\mathbf{0 . 0 0 5}$ \\
\hline Share-Connect & $\mathbf{+ 0 . 7 5 8}$ & $<\mathbf{0 . 0 0 5}$ \\
\hline
\end{tabular}

Collinearity Diagnostics

\begin{tabular}{|c|c|c|c|c|c|c|c|c|c|c|c|}
\hline \multirow[b]{2}{*}{ Model } & \multirow[b]{2}{*}{ Dimension } & \multirow[b]{2}{*}{ Eigenvalue } & \multirow{2}{*}{$\begin{array}{l}\text { Condition } \\
\text { Index }\end{array}$} & \multicolumn{8}{|c|}{ Variance Proportions } \\
\hline & & & & (Constant) & Get & Understand & Share & Method & Identify & Decide & Drive \\
\hline \multirow[t]{3}{*}{1} & 1 & 3.646 & 1.000 & .01 & .01 & .01 & .01 & & & & \\
\hline & 3 & .102 & 5.970 & .14 & .45 & .66 & .06 & & & & \\
\hline & 4 & .082 & 6.660 & .47 & .51 & .27 & .49 & & & & \\
\hline \multirow{5}{*}{2} & 3 & .174 & 6.376 & .23 & .03 & .02 & .25 & .01 & .07 & .08 & .00 \\
\hline & 4 & .163 & 6.578 & .04 & .02 & .11 & .06 & .00 & .06 & .01 & .45 \\
\hline & 5 & .103 & 8.275 & .14 & .01 & .52 & .17 & .16 & .10 & .01 & .09 \\
\hline & 6 & .083 & 9.256 & .10 & .57 & .07 & .22 & .19 & .13 & .04 & .04 \\
\hline & 7 & .069 & 10.151 & .01 & .11 & .22 & .05 & .40 & .45 & .38 & .00 \\
\hline
\end{tabular}

a. Dependent Variable: Connect

Figure 8. Collinearity diagnostics with Connect as dependent variable

A condition index greater than 15 indicates a possible problem, whereas an index greater than 30 suggests a serious problem with collinearity. Figure 8 shows that the condition index for the two models is less than 15, indicating that there are no possible issues with the collinearity for both models. Even though the condition index is higher when more independent variables are introduced in the model, some of the value of condition index is less in Model 2 compared to in Model 1 (e.g. Dimension 4), indicating that the risk of having issues in collinearity is reduced by having the additional four variables. Nevertheless, the highest value of condition index is 11.313 (shown in the last row as Dimension 8), which is still far from the critical value of 15 and above.

Model summary table in SPSS explains the goodness of fit of model. As shown in Figure 9, $\mathrm{R}^{2}$ value for Model 1 is 0.644 , meaning that 64.4 percent $(64.4 \%)$ of variation is explained by the model. The adjusted $\mathrm{R}^{2}$ adjusts for the number of explanatory terms (i.e. independent variables) in a model and increases only if a new independent variable (or variables) improves the model more than would be expected by chance. This is found to be true when the additional independent variables (i.e. cognitive enablers Method, Identify, Decide and Drive) are introduced in the model (i.e. Model 2) alongside the original three independent variables (i.e. Get, Understand and Share). This result is shown in Figure 9, indicated as Model 2.

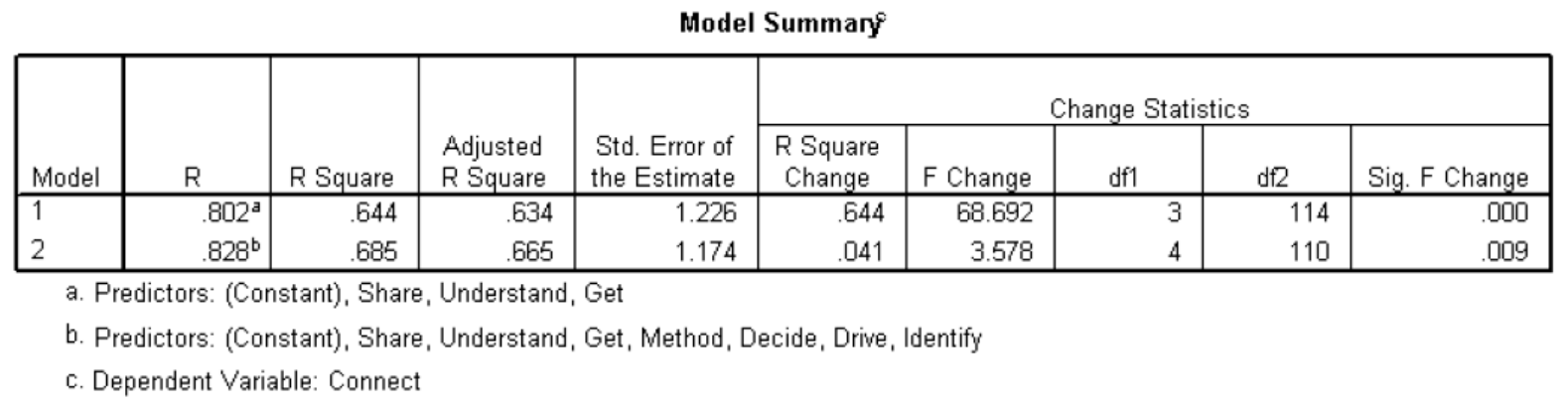

Figure 9. Model summary for GUSC Model 1 and Model 2 with Connect as dependent variable 
The adjusted $\mathrm{R}^{2}$ value for Model 2 is 0.665 (as shown in Figure 9), indicating that 66.5 percent (66.5\%) of variation is explained by the model. This shows an increase of 2.1 percent $(2.1 \%)$ from the value in Model 1 . This proves that the introduction of cognitive enablers as independent variables increases the strength of the model and making it a better fit.

Looking at the case for hypothesis 2 , instead of considering the cognitive enablers as independent variables (i.e. directly influence the value of dependent variable Connect), it is suggested that they are included in the model as control variables or mediating variables (i.e. variables that mediates the relationship between an independent variable and a dependent variable). To prove this, partial correlations analysis is conducted, but it shows a negative result.

As shown in Figure 10, the correlations between Get-Connect, Understand-Connect and Share-Connect decrease as the Method, Identify, Decide and Drive are introduced as control variables. The summary of this result is shown in Table IV.

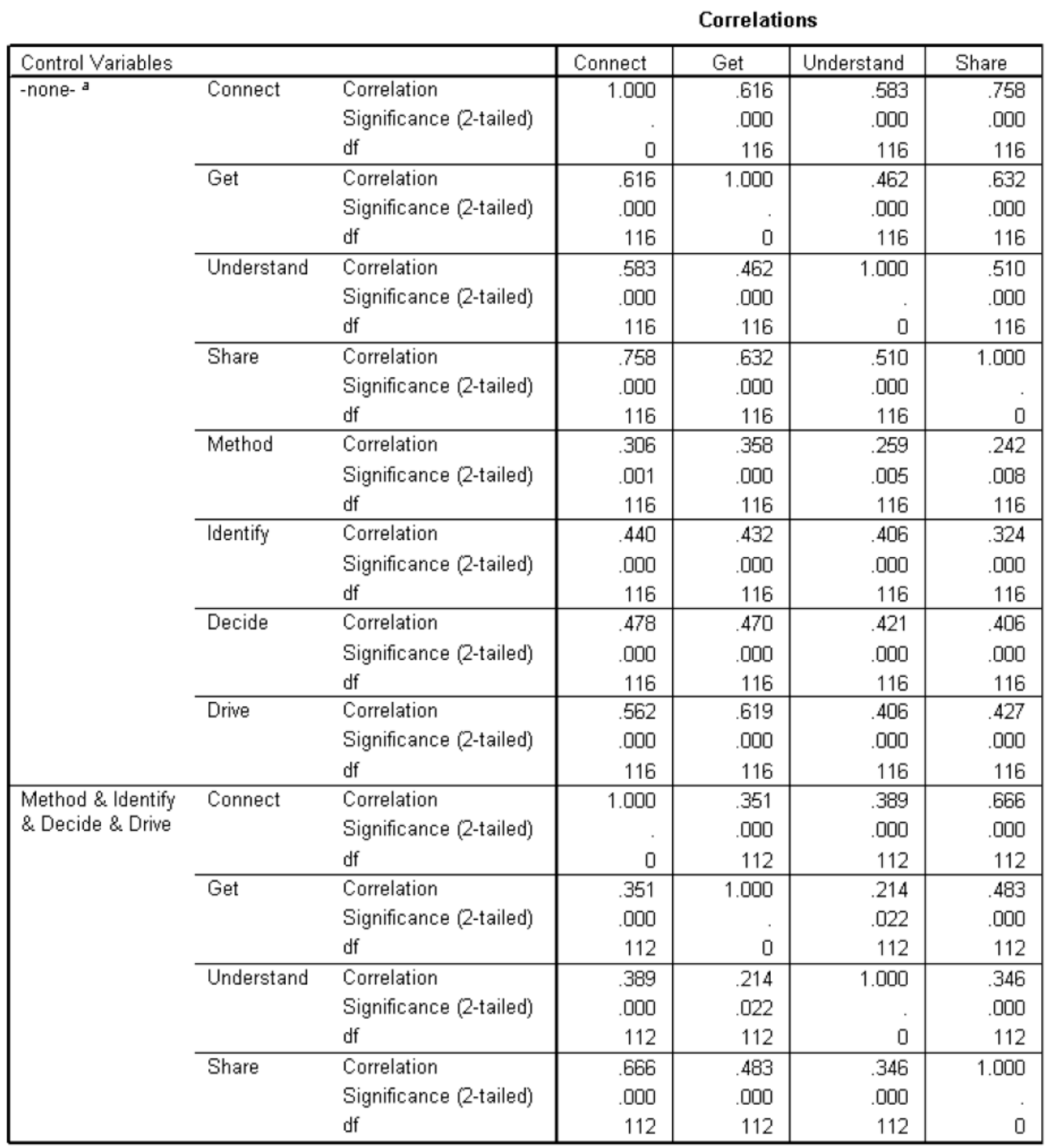

a. Cells contain zero-order (Pearson) correlations.

Figure 10. Correlations between variables in Model 1 and the additional Method, Identify, Decide and Drive as control variables

With the comparison shown in Table IV, the hypothesis H2: Cognitive enablers are the control variables in the GUSC Model is not proven to be true. In fact, the cognitive enablers play a more important role of being part of the whole equation, or in other words they should be considered as independent variables instead of mediating variables (as proven in the Figures 8 and 9). Take note that this is for the case of Connect being defined as dependent variable. (Note: The case may differ if Connect is treated as an independent variable and a different dependent variable is defined). 
Table IV. Relationship between the Variables with Before and After Mediating Variables $(M)$ are introduced

\begin{tabular}{|c|c|}
\hline Without Cognitive Enablers as Mediating Variables & With Cognitive Enablers as Mediating Variables \\
\hline$r($ Get, Connect $)=+\mathbf{0 . 6 1 6}$ & $r($ Get, Connect $\mid M)=+\mathbf{0 . 3 5 1}$ \\
\hline$r($ Understand, Connect $)=+\mathbf{0 . 5 8 3}$ & $r($ Understand, Connect $\mid M)=+\mathbf{0 . 3 8 9}$ \\
\hline$r($ Share, Connect $)=+\mathbf{0 . 7 5 8}$ & $r($ Share, Connect $\mid M)=+\mathbf{0 . 6 6 6}$ \\
\hline
\end{tabular}

On a key note, the cognitive enablers are found to be strong mediating factors for Share-Connect relationship $(+0.666)$. This also indicates the significance of Share-Connect relationship to exist between agents during agent interaction, and the possibility of having the cognitive enablers to ensure this interaction happens. With this reason, even though hypothesis $\mathrm{H} 2$ is not proven to be true, the mediating factors should be totally thrown out of the whole equation because it still plays some significant roles that will need further investigation.

Even though the original model is to have Get, Understand, Share and Connect to be the independent variables for effective PKM, the data collected from the questionnaire survey in this particular research gives an overall conclusion that Connect should be the dependent variable instead of 'Effective PKM'. From the results presented in this section, a conclusion can be made that Connect is a significant role that determines the whole PKM to be effectively performed by individual knowledge workers. Hence, hypothesis H3: Connect is the most significant role in mediating human's $\boldsymbol{P K M}$ is proven to be true, which depends on all other roles (also referred to as independent variables in this research) to fully perform effective PKM processes.

\section{Discussions}

From the proven hypotheses, the agent functions are clearly defined and sorted according to a proper sequence, considering the preliminary findings in PKM process framework and the quantitative results. The regression analysis results also show how the functions and/or multiple agents should be interacting. Since Connect is found to be the most significant role among the four roles, and the Pearson correlation $(r)$ values for Get- Connect and Share-Connect are high (i.e. above +0.6 as shown in Table III), the following model is formed as Figure 11.

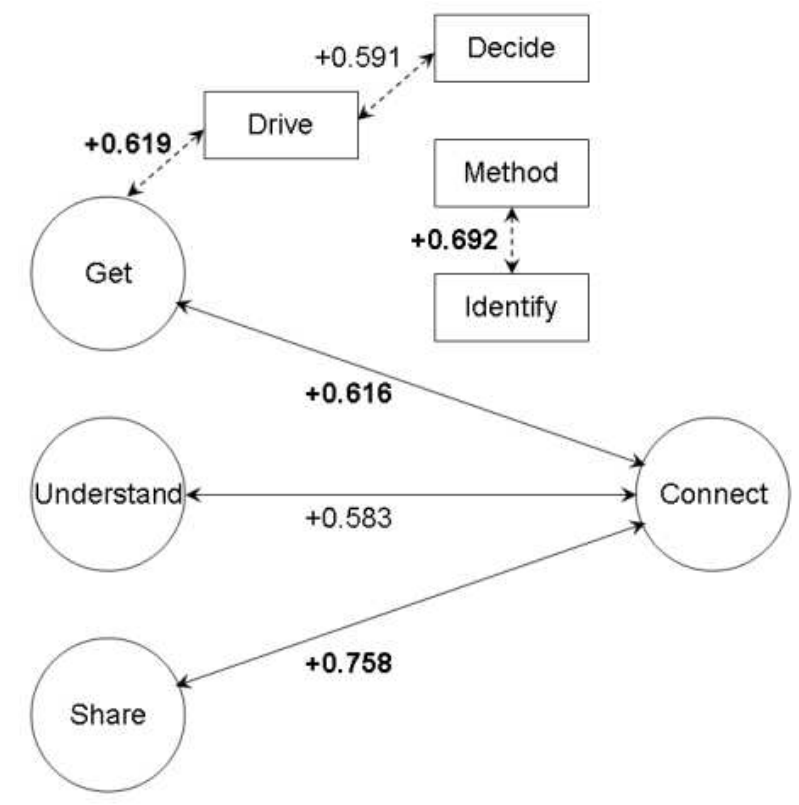

Figure 11. Proven model of GUSC with cognitive enablers

Figure 11 shows the interactions between role agents that are proven to be necessary, with Get-Connect and ShareConnect having strong relationships (i.e. +0.616 and 0.758 respectively), whereas the relationship of UnderstandConnect holds an almost strong value $(+0.583)$. Among the cognitive enablers, the strongest relationship they have with the agent roles is Get-Drive, which holds the value of +0.619 . Other significant relationships are Drive-Decide $(+0.591)$ that is less strong, and Method-Identify (+0.692). (Note: The case may differ if the cognitive enablers are included in the model as mediating factors for Share-Connect.) 
From the proven model in Figure 11, the Drive notion is expected to be strongly embedded in the Get role agent. In order to assist the Drive enabler, a Decide feature or capability is the next challenge to be implemented. Overall, the Method and Identify enablers should exist in the agent environment to guide the agents on each task performance.

The elaboration on Figure 11 can be presented in a nodal form as shown in Figure 12, where the Get, Understand and Connect agents is portrayed in Node 1 representing Human Knowledge Seeker, whereas Share agent is portrayed in Node 2 representing Human Knowledge Expert.

This node-based model is designed to plan a multi-agent system for PKM, based on the GUSC model that is proven to be logically implementable as agent roles. The cognitive enablers (i.e. Method, Identify, Decide and Drive) are within the agent environment, with distance between Get agent and Drive notion to be very close indicating the high reliance on Get agent to have the Drive capability in order to fulfil the mediating task of get/retrieve knowledge on behalf of the human counterpart. Decide enabler is also shown to be close to the Drive notion, indicating the required Decide capability if the Get agent can be programmed to perform more effectively. Method and Identify enablers are the set of rules that are needed within the agent environment in a node, as guides for the agents in performing their tasks on behalf of the human counterpart.

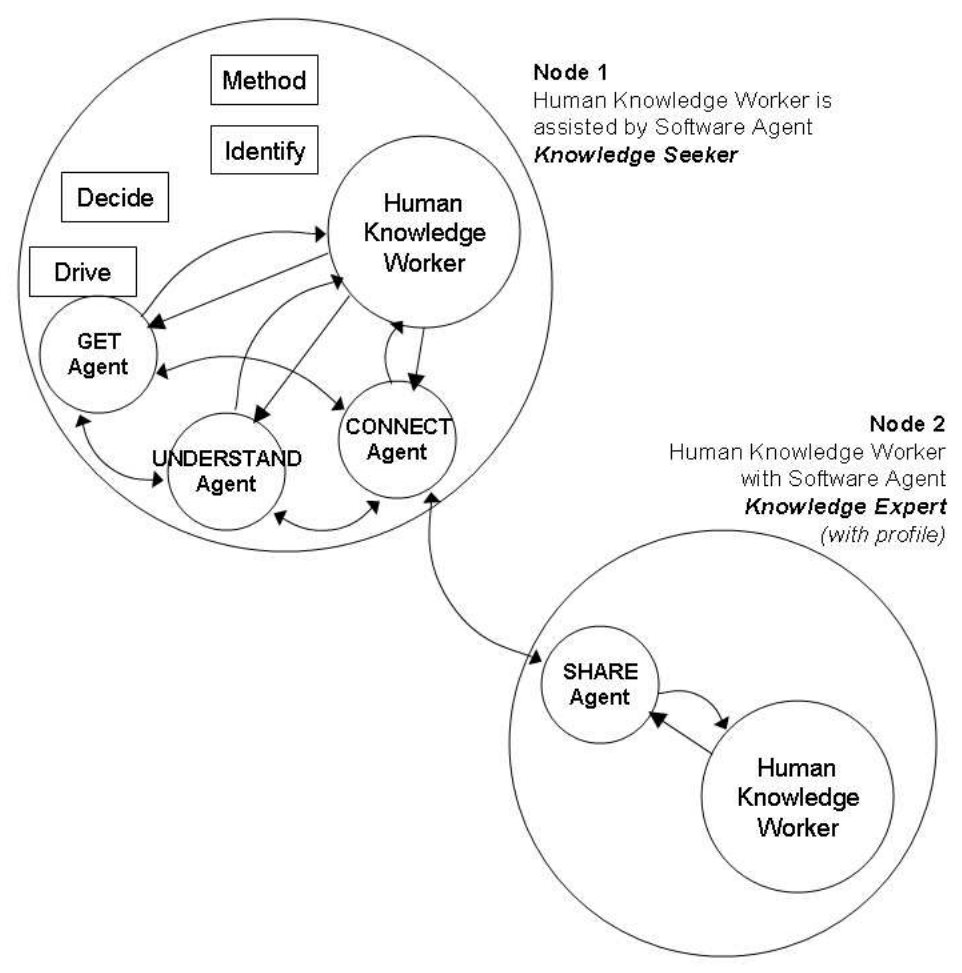

Figure 12. Multiple agents with GUSC roles in nodal form

\section{Conclusion and Further Work}

It is recommended that the simulation of Get-Connect-Share interactions among the agents are to be first completed, with Drive notion embedded on Get agent, and Method and Identify to be the rules in the agent environment. This is followed by the second implementation to prove and simulate how agent can Understand for Understand-Connect, which will need the agent to have the learnability as part of its intelligence. For the second implementation as well, the Decide capability of an agent should be experimented against the strong notion of Drive, and the success for simulating Decide capability is highly dependent on the success of simulating Method, Identify and Drive. 


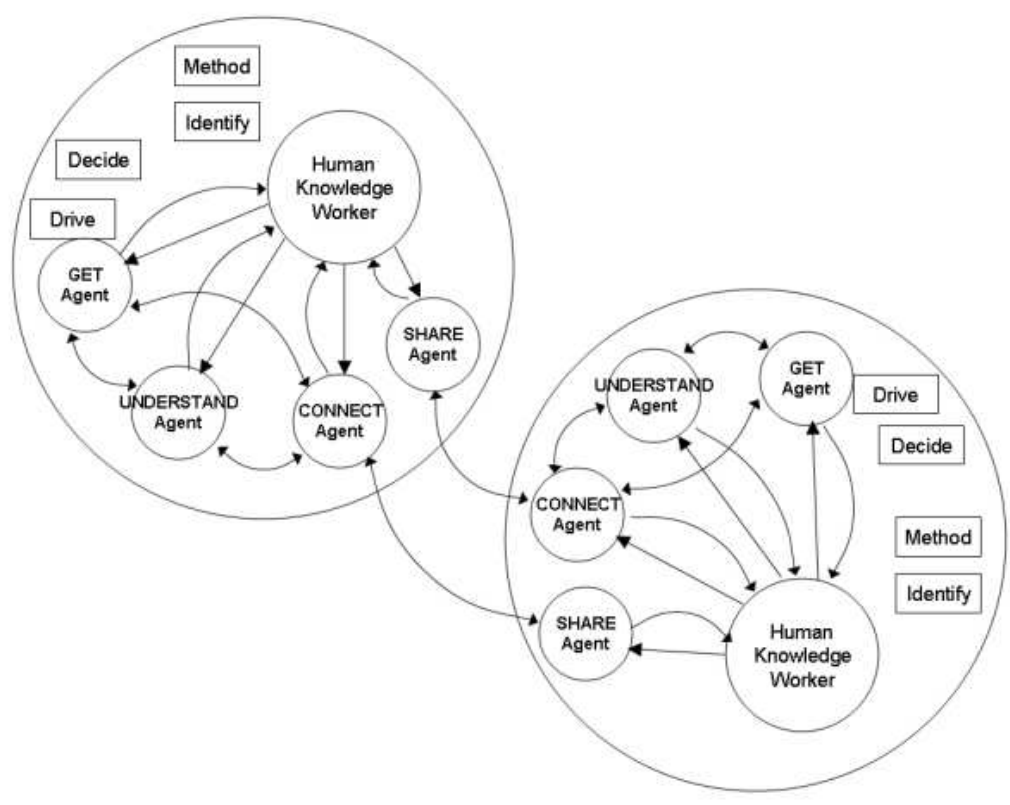

Figure 13. Viable multi-agent system for PKM based on GUSC Model

In expanding the work proposed in this paper, the Get, Understand, Share and Connect agent should exist in one node to completely assist the PKM processes of a human knowledge worker. In general, the overall multi-agent system for PKM can be a viable system, as shown in Figure 13. In our further work, we shall simulate the GUSC model based on the findings of this research. Details of the simulation results will be analysed to enhance the GUSC model for a multiagent system development framework.

\section{References}

Solachidis, V., Mylonas, P., Geyer-Schulz, A., Hoser, H., Chapman, S., Ciravegna, F., et al., n.d. Collective Intelligence Generation from User Contributed Content. In: A. Fink et al., ed., 2010. Advances in Data Analysis, Data Handling and Business Intelligence, Studies in Classification, Data Analysis, and Knowledge Organization, Berlin: Springer-Verlag, pp.765-774.

Sondari, M.C., 2013. Personal Knowledge Management 2.0. International Journal of Social Science and Humanity, 3(4), pp.426-428.

Zhang, Z., 2008. Personalising organisational knowledge and organisationalising personal knowledge. Online Information Review, 33. pp.237-256.

Myint, D., 2004. PKM: the starting blocks for KM. Inside Knowledge Magazine, 7.

Pettenati, M.C., Cigognini, E., Mangione, J. and Guerin, E., 2007. Using social software for personal knowledge management in formal online learning. Turkish Online Journal of Distance Education, 8, pp.52-65.

Razmerita, L., Kirchner, K. and Sudzina, F., 2009. Personal knowledge management: The role of Web 2.0 tools for managing knowledge at individual and organisational levels. Online Information Review, 33, pp.1021-1039.

Verma, S., 2009. Personal Knowledge Management: A Tool to Expand Knowledge about Human Cognitive Capabilities. IACSIT International Journal of Engineering and Technology, 1(5), pp.435-438.

Avery, S., Brooks, R., Brown, J., Dorsey, P. and O' Connor, M., 2001. Personal knowledge management: framework for integration and partnerships. In: Association of Small Computer Users in Education Conference. North Myrtle Beach, South Carolina, United States, June 2001, pp.29-39.

Grundspenkis, J., 2007. Agent based approach for organization and personal knowledge modelling: Knowledge management perspective. Journal of Intelligent Manufacturing, 18, pp.451-457.

Jarche, H., 2009. Sense-Making with PKM. Harold Jarche - shining a light on workplace transformation, [online] 12 March. Available at: < http://www.jarche.com/2009/03/sense-making-with-pkm/> [Accessed 08 September 2014].

Jarche, H., 2010. PKM in 2010. Harold Jarche - shining a light on workplace transformation, [online] 27 January. Available at: < http://www.jarche.com/2010/01/pkm-in-2010/> [Accessed 08 September 2014].

Martin, J., 2000. Personal Knowledge Management. In: Martin, J. and Wright, K., ed., 2000. Managing Knowledge: Case Studies in Innovation. [pdf] Edmonton: Spotted Cow Press. Available at: <http://www.spottedcowpress.ca/ KnowledgeManagement/pdfs/06MartinJ.pdf $>$ [Accessed 08 September 2014].

McFarlane, D.A., 2011. Personal Knowledge Management (PKM): Are We Really Ready? JKMP, 12 (3), 2011.

Ismail, S. and Ahmad, M.S., 2012, Effective Personal Knowledge Management: A Proposed Online Framework. World Academy of Science, Engineering and Technology, International Science Index 72, International Journal of Social, Management, Economics and Business Engineering, 6(12), pp.723 - 731. 
Nonaka, I. and Takeuchi, H., 1995. The knowledge creating company: How Japanese companies create the dynamics of innovation, New York: Oxford University Press.

Ismail, S. and Ahmad, M.S., 2011. Emergence of Social Intelligence in Social Network: A Quantitative Analysis for Agent-mediated PKM Processes, In: Proceedings of the 5th International Conference on IT \& Multimedia at UNITEN (ICIM $\mu$ 2011). Putrajaya, Malaysia, 14-16 November 2011.

Awad, E.M. and Ghaziri, H.M., 2004. Knowledge Management. New Jersey: Pearson Education Ltd.

Bradshaw, J.M., Carpenter, R., Cranfill, R., Jeffers, R., et al., 1997. Roles for Agent Technology in Knowledge Management: Examples from Applications in Aerospace and Medicine. AAAI Technical Report SS-97-01, pp.9-16.

Coen, M.H., 1991. SodaBot: A Software Agent Construction System. Cambridge, MA: MIT AI Laboratory.

Russell, S. and Norvig, P., 1995. Artificial Intelligence: A Modern Approach. Englewood Cliffs, New Jersey: Prentice-Hall, 1995.

Gilbert, D., Aparicio, M., Atkinson, B., Brady, S., et al., 1995. IBM Intelligent Agent Strategy.

Maes, P., 1995. Artificial Life Meets Entertainment: Life like Autonomous Agents. Communications of the ACM, 38, pp.108-114.

Jennings, N.R., Faratin, P., Lomuscio, A.R., Parsons, S. Sierra, C. and Wooldridge, M., 2000. Automated Negotiation: Prospects, Methods and Challenges, International Journal of Group Decision and Negotiation, pp.1-30.

Paprzycki, M. and Abraham, A., 2003. Agent Systems Today: Methodological Considerations. International Conference on Management of e-Commerce and e-Government, pp.1-7.

Wooldridge, M.J. and Jennings, N.R., 1995. Intelligent Agents: Theory and Practice. The Knowledge Engineering Review, 10.

van Elst, L., Dignum, V. and Abecker, A., 2003. Towards Agent-Mediated Knowledge Management. Lecture Notes in Computer Science, 2926, Springer.

Guizzardi, R.S.S., Aroyo, L. and Wagner, G., 2003. Agent-Oriented Knowledge Management in Learning Environments: A Peer-to-Peer Helpdesk Case Study. AMKM 2003, LNAI 2926, pp.57-72.

Ismail, S., Ahmad, M.S. and Hassan, Z., 2012. Social Intelligence in Personal Knowledge Management using Software Agents. Journal of Research and Innovation in Information Systems (JISRI), 1, pp.1-10.

Green W. and de Ruyter, B., 2009. The Design and Evaluation of Interactive Systems with Perceived Social Intelligence: Five Challenges. AI \& Society, 25, pp.203-210.

Wiedermann, 1995, pp.441. In: U. Flick, ed., 2009. An Introduction to Qualitative Research, Chennai: Sage, p.119.

Field, A., 2000. Discovering Statistics using SPSS for Windows, London: Thousand Oaks, Sage Publications. 